\title{
Kernos
}

Revue internationale et pluridisciplinaire de religion grecque antique

26 | 2013

Varia

\section{Attilio Mastrocinque, Concetta Giuffrè Scibona (éd.), Demeter, Isis, Vesta and Cybele, Studies in Greek and Roman Religion in Honour of Guilia Sfameni Gasparro}

Laetizia Puccio

\section{(2) OpenEdition \\ Journals \\ Édition électronique \\ URL : http://journals.openedition.org/kernos/2175 \\ DOI : 10.4000/kernos. 2175 \\ ISSN : 2034-7871 \\ Éditeur \\ Centre international d'étude de la religion grecque antique}

Édition imprimée

Date de publication : 10 octobre 2013

Pagination : 437-439

ISSN : 0776-3824

\section{Référence électronique}

Laetizia Puccio, «Attilio Mastrocinque, Concetta Giuffrè Scibona (éd.), Demeter, Isis, Vesta and Cybele, Studies in Greek and Roman Religion in Honour of Guilia Sfameni Gasparro », Kernos [En ligne], 26 I 2013, mis en ligne le 10 octobre 2013, consulté le 02 mars 2021. URL : http://

journals.openedition.org/kernos/2175; DOI : https://doi.org/10.4000/kernos.2175

Ce document a été généré automatiquement le 2 mars 2021.

Kernos 


\title{
Attilio Mastrocinque, Concetta Giuffrè Scibona (éd.), Demeter, Isis, Vesta and Cybele, Studies in Greek and Roman Religion in Honour of Guilia Sfameni Gasparro
}

\author{
Laetizia Puccio
}

\section{RÉFÉRENCE}

Attilio Mastrocinque, Concetta Giuffrè Scibona (éd.), Demeter, Isis, Vesta and Cybele, Studies in Greek and Roman Religion in Honour of Guilia Sfameni Gasparro, Stuttgart, Franz Steiner Verlag, 2012. 1 vol. $17 \times 24 \mathrm{~cm}, 248$ p. (Potsdamer Altertumswissenschaftliche Beiträge, 36). ISBN : 978-3-515-10075-5.

1 Cet ouvrage en l'honneur de Giulia Sfameni Gasparro s'accompagnera d'un second opus ouvert à des contributions libres sur l'histoire des religions et qui contiendra la bibliographie de la chercheuse italienne. Le premier volume est consacré à des divinités féminines, car elles ont été au centre des préoccupations de cette dernière. Les quatorze articles sont divisés en quatre parties, chacune dévolue à une déesse, à savoir Déméter, Isis, Vesta et Cybèle.

2 Alberto Bernabé nous plonge tout d'abord dans une analyse de la représentation orphique de la vie dans le royaume de Perséphone, perçu comme le modèle d'un monde idéal uniquement réservé à quelques initiés. Suivant une vision individuelle et sociale de la problématique, l'A. a construit son discours sur base de diverses sources: des passages tirés de tablettes d'or trouvées en Grande Grèce et ailleurs, des fragments de poèmes attribués à Orphée, des considérations de Platon, comme d'autres auteurs anciens, et des images peintes sur de la céramique provenant du sud de l'Italie. 
3 La dernière étude consacrée à Déméter dans la cité de Mégare date de 1934르. Depuis lors, la documentation n'a cessé de croitre tout comme la manière d'appréhender et de questionner l'histoire de la religion grecque. Face à ces nouvelles considérations d'ordre méthodologique, Jan $\mathrm{N}$. Bremmer décide de réviser l'ensemble des sources relatives à la déesse. In fine, il postule à Mégare, comme dans d'autres cités grecques, l'existence d'une Déméter qui n'est pas unique, mais qui présente plusieurs facettes qu'il serait bon d'analyser, notamment à travers l'étude des épiclèses.

4 Louise Bruit Zaidman propose de repartir de l'histoire de Koré-Perséphone afin d'insister sur la façon dont mythes, cultes et représentations mettent en scène sa relation à la Mère et à l'Époux. À travers l'Hymne homérique à Déméter et le culte rendu aux deux déesses à Éleusis et hors d'Éleusis, l'A. démontre comment Koré-Perséphone, entre Déméter - sa mère - et Hadès - son époux -, crée une liaison entre les enfers et le monde des vivants ainsi qu'entre les hommes et les dieux.

5 Concetta Giuffré Scibona soumet, quant à elle, un article sur la place des déesses Déméter et Athéna dans la colonie de Gela. Elle insiste d'abord sur l'importance du rôle des cultes indigènes lors de l'établissement d'une colonie. Elle fait également remarquer la relation entre les tentatives visant à préserver ces cultes dans de nouvelles conditions et la réaction face aux besoins personnels et aux innovations locales. Cette situation a très souvent entraîné l'introduction de nouveaux éléments et témoigne, de la sorte, de la vitalité de l'expérience religieuse polythéiste.

6 Nous changeons de déesse avec Laurent Bricault et l'étude des associations créées en Occident autour de l'autel d'Isis. L'A. part d'un extrait des Métamorphoses d'Apulée, dans lequel est évoqué le collège des pastophores, pour ensuite définir le rôle, le mode de fonctionnement, les membres et les caractéristiques de ces associations. Moins nombreuses qu'en Orient, elles sont pour les fidèles un moyen de se réunir et elles présentent aux époques tardo-républicaine et impériale les mêmes éléments constitutifs que tout collège romain.

7 Attilio Mastrocinque consacre également un article à Isis, mais à travers Neotera et son iconographie. Afin de saisir la personnalité de cette déesse d'époque impériale, l'A. décide d'abord de présenter toute la documentation qui s'y rapporte (gemmes, monnaies, inscriptions et extraits d'auteurs anciens). La déesse ne fait pas partie de l'ancestrale religion pharaonique, mais elle correspond à une création de cléopâtre, d'où son identification possible avec Isis et Aphrodite. D'après Mastrocinque, Neotera est une adaptation théologique issue de la tradition éleusienne d'Alexandrie.

Souvent associées au combat de l'aristocratie sénatoriale à Rome contre la montée du christianisme à la fin de l'Antiquité, les divinités d'origine orientale sont passées au crible par Carla Sfameni dans leur dimension " privée ». Devant les mesures officielles de fermeture des temples païens prises à partir du IV siècle, il semble, d'après la documentation, que les "cultes orientaux» ont été "privatisés" afin de pouvoir encore être pratiqués.

9 Gaëlle Tallet apporte une nouvelle interprétation d'une scène conservée au Musée égyptien du Caire. Celle-ci a été gravée sur un relief d'époque romaine divisé en deux registres (JE 30001). Sur le registre supérieur figure une divinité radiée, assise sur un trône face à un prêtre et entourée, vraisemblablement, de deux prêtresses; tandis que, au registre inférieur, sont alignés cinq soldats. La présence d'un crocodile dans les bras de la divinité permet de l'associer à Sobek Ra Horus, le fils d'Isis. D'après l'A., cette 
scène pourrait dépeindre un ancien rituel grec, le semania. Elle aurait été offerte par une association religieuse de soldats dans un sanctuaire local.

Nous changeons de registre avec la déesse Vesta et le monde des Vestales dans lequel nous plonge l'article de Silvia Baschirotto. Liées à la fondation et à la protection de l'Urbs, les prêtresses étaient sacrifiées, selon l'hypothèse de l'A., afin de garantir la sauvegarde de la cité et la restauration de la pax deorum. Partant de la punition imposée aux Vestales adultères, la chercheuse fonde son exposé sur une étude comparée avec des pratiques similaires observées dans d'autres villes italiennes et grecques, ainsi qu'en Asie orientale, dans les Balkans et dans le monde africain.

Dans son article sur les Flamines, les Saliens et les prêtresses de Vesta, Jörg Rüpke met l'accent sur des interprétations singulières du rôle de certains prêtres à la fin de l'ère républicaine. À travers quelques exemples, l'A. montre avec érudition que les difficultés liées à certaines charges sacerdotales n'ont pas été un frein pour les Romains (en particulier les patriciens), car la carrière religieuse était tout aussi attractive et valorisante que la carrière politique.

Richard Gordon introduit une dernière divinité d'origine orientale, Magna Mater, à travers de nouveaux textes de malédiction rédigés en latin. Ils proviennent des régions du Portugal et d'Allemagne, et sont adressés conjointement à la déesse et à son époux, Attis. Ce qui rend ces écrits particulièrement intéressants pour l'étude du culte métroaque, c'est qu'ils n'ont pas un sens votif traditionnel. Cette fonction de dieux vengeurs est une corde supplémentaire dans le chef du couple phrygien. Elle ne trouve pas son origine dans la mythologie, mais elle est attestée à travers l'iconographie.

La problématique de l'origine du nom de Cybèle dans la littérature latine remonte à l'introduction du culte de la déesse à Rome à la fin du III ${ }^{e}$ s. a.C. D'après Charles Guittard, Cybèle entre officiellement dans le panthéon romain sous le nom de Magna Mater Idaea. Le recours à d'autres formes nominales en poésie ou en prose latines est envisageable. Dans ce cas, d'après l'A., il ne fait pas référence à la déesse romaine, mais trahit les origines de Cybèle.

Depuis leur découverte en 1985 à Arellano dans le nord de la province de Saragosse, deux reliefs figurant la tête d'un taureau ont été identifiés à des autels tauroboliques et donc associés aux cultes de Cybèle et Attis. Pourtant, d'après F. Marco Simón, en cette fin de $I^{e}$ siècle, il semble plus pertinent de les rapprocher de l'empereur Julien (360-363). Le chercheur fonde son argumentaire sur une célèbre pièce de monnaie sur laquelle figure le souverain. À l'envers, se trouve un taureau debout face vers l'avant, surmonté de deux étoiles et entouré de la légende Securitas Rei Pub(licae). L'A. réfute tout d'abord les propos de Prudence qui font de Julien un modèle du prêtre «taurobolique ». Il analyse ensuite les deux faces de la pièce dont le message véhicule, selon lui, « a 'language that strongly mobilises social practice' ».

Enfin, le volume se termine par un article de Robert Turcan qui nous invite à suivre le circuit rituel de la lauatio à travers un médaillon de bronze frappé sous le règne d'Antonin le Pieux. L'avers porte le buste de Faustine Mère tandis que, au revers, le couple Cybèle et Attis siège dans un plaustrum massif en route pour l'Almo, un petit affluent du Tibre au sud de Rome. La pièce parfaitement décrite, l'A. se demande quel était le parcours suivi lors de ce cérémonial. Sur le revers du médaillon, un temple circulaire semble appartenir à Vesta et correspondre plus exactement à l'aedes qui s'élevait à côté du palatin. Turcan précise que le rituel de la lavatio avait une signification eschatologique et sotériologique, car il garantissait la victoire des vivants 
sur la mort. Il était donc utilisé par les autorités romaines comme un symbole d'éternité.

\section{NOTES}

1. Hannell K., Megarische Studien, Lund, 1934.

\section{AUTEURS}

\section{LAETIZIA PUCCIO}

Archives de l'État à Liège 